\title{
Scaffolding Theory Study Based on Multimodality*
}

\author{
Jing Ji \\ Jilin Institute of Chemical Technology \\ Jilin, China
}

\author{
Chen Luo \\ Zunyi Normal University \\ Zunyi, China
}

\begin{abstract}
Based on the research of multimodal discourse theory and scaffolding theory, this thesis summarizes and analyzes the modes of combining two theories in the second language acquisition process, and summarizes the application method design of multimodal auxiliary scaffolding theory. This thesis will break the current situation of less research on the combination of the two theories, further study the relationship between various modalities and how to combine research and exploration with the scaffolding theory, change the traditional teaching mode, and change the "teacher-centered" to "student-centered", to stimulate students' interest in learning, enhance students' enthusiasm and initiative, strengthen students' memory and promote students' understanding and internalization of knowledge, thus promoting students' comprehensive improvement of comprehensive capabilities such as independent exploration, collaborative learning and meaning construction.
\end{abstract}

Keywords-multimodal theory; scaffolding theory; applied research

\section{INTRODUCTION}

With the development of society and education, the research on multimodal theory and scaffolding theory is gradually enriched, but there are few studies on the combination of the two theories. The existing studies mainly focus on the theoretical research with less empirical research. There are more static text studies and less dynamic research. The relationship between various modalities and how to combine well with the scaffolding theory needs to be developed and explored. How to apply the two theories to college English teaching then?

Taking the college English writing teaching in China as an example, the teaching status is not optimistic. Traditional, "teacher-centered" teaching methods are still used. The students are in a passive, subordinate position and their subjective initiative is not mobilized, losing interest in the writing class. Under the guidance of constructivist learning theory, this thesis combines the scaffolding teaching theory with multimodal teaching theory to construct a multimodal auxiliary scaffolding teaching model to cultivate students' language skills.

*Fund: This thesis is used for closing the project of "Scaffolding Theory Study Based on Multimodality" of the Social Science Research Project of Jilin Institute of Chemical Technology (Project No.: JHYHZ [2017] No. 061)

\section{The SCAFFOLdING TeACHING TheORY}

Scaffolding theory has a wide range of influences in the fields of linguistics and applied linguistics. Scaffolding teaching is a new teaching idea based on constructivist learning theory. This theory was first proposed by the cognitive psychologist Bruner in the 1950s. The constructivist theory and the zone of proximal development form the basis of the scaffolding theory. Constructivism emphasizes the importance of building a knowledge system through existing experience and the social and cultural factors of learners in the learning process. The zone of proximal development was first proposed by Vygotsky. "The difference between the actual levels of cognitive development determined by the learner's ability to solve problems independently and the potential level of cognitive development shown under the guidance of adults or in cooperation with peers of strong ability is the "zone of proximal development", and teaching must be in the scope of "zone of proximal development".

The scaffolding in the scaffolding teaching is the meaning of help. The scaffolding is equivalent to constructing the bracket during the architectural process, which is beneficial to the learner's upward climbing, and the learner can reach the potential development level by crossing the zone of proximal development.

Scaffolding teaching indicates that teachers set up scaffold for students in the "zone of proximal development", which means that teachers provide appropriate help and support for students to complete their own learning tasks, so that they can climb up the scaffold and step over the "zone of proximal development" from the actual development level to reach the potential level of cognitive development and grow into an independent learner, and finally the teacher withdraws from the scaffold. In short, scaffolding teaching means that the teacher guides the teaching through the scaffold (teacher's help), enabling the students to master, construct and internalize the knowledge and skills they have learned so that they can carry out higher levels of cognitive activities.

The scaffolding teaching theory is generally divided into five steps:

- First: constructing a scaffold according to the zone of proximal development theory and the content of the current learning 
important to interpret the multimodal discourse theory and understand its research status. situation

- Third: students' independent exploration stage

- Fourth: grouping and organizing students' group learning

- Fifth: evaluating the learning effect of the students

\section{THE MULTIMODAL TEACHING THEORY}

A modality is a way of interacting with the outside through these sensory systems such as sight, hearing, and touch. Multimodality refers to the interaction of three or more sensory systems. The basis of multimodal teaching theory is multimodal discourse analysis. Among them, multimodal discourse refers to the use of visual, auditory, tactile and other sensory organs, combined with the use of images, video, audio and other resources for communication. Pictures, videos, and sounds can also be called social symbols other than language, expressing social significance. This mode in which multiple symbol systems are used simultaneously is called multimodal mode. Hu Zhuanglin's definition of multimodality is that modal means that in addition to text, there are symbolic utterances such as images and diagrams, or meaning texts that are implemented by more than one symbolic encoding.

With the emergence and development of advanced network teaching technology, the way of information transmission has been transformed from a traditional single text form into a complex form of multiple modes. Symbols such as images, colors, and music that were once considered as sub-language have been involved in the construction of meaning in conjunction with linguistic symbols in modern communication. The collection of multimodal symbols such as pictures, videos, audio, texts, languages, etc. can stimulate students' sight, hearing, and touch, so that they can truly understand the language environment they are learning, in order to effectively improve the teaching efficiency and the teaching atmosphere is more relaxed and enjoyable, which will greatly stimulates students' interest and enthusiasm for learning. The foreign language teaching environment has been greatly improved, and English teaching has entered a multimodal teaching from single mode teaching. Multimodal teaching can create a vivid, lively and pleasant learning atmosphere for students, which can greatly stimulate students' learning enthusiasm.

Multimodal discourse analysis enables the integration of language and other meaningful symbol resources, so that readers can not only see the role of language systems in language communication, but also realize the role of multiple symbol systems such as images, thus more accurately interpreting the significance of words. In recent years, multimodal discourse studies have sprung up. Multimodal discourse analysis has been widely used in sociology, anthropology, aesthetics, journalism, semiotics and other fields. The research object has also expanded from a single word language to a variety of social symbol systems such as pictures, videos, and architectural design. Therefore, it is

\section{THE COMBINATION AND PRACTICAL APPLICATION OF MULTIMODAL THEORY AND SCAFFOLDING THEORY}

So far, there have been few studies on the combination of the two theories. The existing studies mainly focus on the theoretical research with less empirical research. There are more static text studies and less dynamic research. The relationship between various modalities and how to combine them with scaffolding theory need to be developed and explored. This thesis will further explore and explain the relationship between various modalities and how to combine research and exploration with the scaffolding theory. Through the combination of multimodal theory and scaffolding theory, it is possible to change the traditional teaching mode, change the "teacher-centered" to "studentcentered", stimulate students' interest in learning, enhance students' enthusiasm and initiative, strengthen students' memory and promote students' understanding and internalization of knowledge, thus promoting the comprehensive improvement of students' independent ability, independent learning, collaborative learning and meaning construction.

In the context of English teaching reform, the multimodal auxiliary scaffolding method is applied to college English teaching, which can be used as an example. On the one hand, the characteristics of the scaffolding teaching method can be used to change the traditional "cramming education" teaching mode to mobilize students' subjective initiative, improve students' participation in classroom teaching, change classroom learning methods based on indirect English teaching experience, and promote the improvement of comprehensive ability of students' independent inquiry and collaborative learning. It can diversify and rationalize the methods of evaluating college English translation teaching. On the other hand, using multimodality to stimulate students with multiple senses can help stimulate consciously guide students to pay attention to relevant information in the field of knowledge, to achieve the purpose of expanding students' knowledge and improving students' comprehensive quality. It can be said that it is of great significance to introduce multimodal scaffolding teaching into college English teaching.

\section{DESIGN EXAMPLES OF MULTIMODAL AND SCAFFOLDING TEACHING THEORY APPLIED TO CLASSROOM TEACHING}

\section{A. Design of College English Writing Class Mode Based on the Combination of Multimodal Theory and Scaffolding Theory}

In view of the current worrying situation of college English writing teaching, this paper will try to combine scaffolding teaching and multimodal teaching, with scaffolding teaching as the mainstay and multi-mode teaching as the supplement, and carry out multimodal students' interest in learning, enhance students' memory, and 
auxiliary scaffolding method with the help of multimedia network technology platform. This model will combine the advantages of both multimodal teaching and scaffolding teaching modes. On the one hand, scaffolding teaching mode can completely change the traditional "teacher-centered" writing teaching model, emphasizing "student-centered", and students are no longer passive recipients of knowledge, but the subject of independent learning. With the help of the scaffold, students can improve their writing ability through independent exploration and mutual cooperation. On the other hand, through multimodal auxiliary teaching, students can experience interactive surrounds of text, sound, animation, images, etc. The colorful multimodal teaching resources can fully mobilize students' senses of sight, hearing and other senses, stimulate students' interest in learning English writing, and strengthen learning effects.

In the multimodal auxiliary scaffolding college English writing teaching mode, the role of teachers is to use the rich and colorful multimodal teaching resources on the network to build a good scaffold for students, so that students can climb step by step through these scaffolds to help them cross zone of proximal development in order to reach a new level of writing. In the multimodal auxiliary scaffolding college English writing teaching mode, the teacher should set up the following scaffolds for the students.

1) Using multimodal teaching resources to build knowledge scaffolds:

After the teacher has arranged the writing task for the students, it is necessary to build a knowledge scaffold for the students. The knowledge scaffold includes examples and explanations about the writing knowledge and writing skills, such as how to draw up the outline, how to write the topic sentence, how to expand the paragraph, etc. In addition, students can also be explained with some of the sentence patterns related to the writing theme. In the usual writing training, the author finds that many students can't find the proper sentence layout; as a result, the sentence pattern students use is monotonous with a lot of simple sentences. When teachers build knowledge scaffolds for students, they should avoid simple and boring explanations. Instead, they should make full use of multimedia network technology platform to implement multimodal teaching. Teachers can make teaching content into multimodal PPT courseware. When designing courseware, teachers can organically combine elements such as text, graphics, images, colors, animations, videos, background music, etc., to bring students multiple senses of sight, hearing, etc., fully mobilize the students' senses and stimulate their interest in learning, enhancing students' memory and cognitive comprehension of relevant writing knowledge and skills.

\section{2) Building a positive psychological scaffold:}

Active psychological scaffold means that teachers should be good at mobilizing the emotions of students and create a relaxed and pleasant writing teaching environment. Psychologists believe that emotions occupy the entire psychological activity and real life of human beings, and are the driving force of the whole person's activities. In teaching, students' emotions are an important factor influencing the effectiveness of teaching. Therefore, teachers should observe the mental state and writing situation of the students at any time during the teaching process, encourage and praise them in a timely manner, and provide necessary assistance when students encounter difficulties in writing, so that they can keep positive learning attitude all the time during the writing process. In addition, teachers must pay attention to the difficulty of writing assignments for students when setting up psychological scaffold, and the difficulty shouldn't be too large. Teachers should set up writing tasks in the "zone of proximal development" of students' writing level; otherwise it will cause students' negative emotions such as anxiety, nervousness, irritability, etc. In addition, the design of the topic is also very important. Teachers should fully consider the psychological characteristics and age characteristics of students when designing essay topics, understand their hobbies. Generally speaking, the essay topics should be as close as possible to the student life and the times, which can stimulate students' desire to write, so that students will be happy to learn and willing to write, and they will be full of energy and interest from beginning to end.

\section{3) Building "student-student interaction" scaffolds:}

For the scaffolding teaching, the cooperative learning between the peers is very important. The peers can achieve a comprehensive understanding of the current knowledge in mutual consultation, mutual help and mutual discussion, and complete the construction of the learned knowledge. Therefore, in the teaching of scaffolding college English writing, teachers should be good at building effective "student-student interaction" scaffolds, and jointly explore and improve students' writing ability through "studentstudent cooperation".

Before the start of the writing class, teachers will divide the students into certain groups with five people of every group. When grouping, teachers should try to make each group's level close. Each group should have students with different levels of excellent, medium and poor. The different levels of students will help them to help each other and improve together. And students should be organized to sit in groups. Each group is headed by a classmate and he will be responsible for organizing the discussion of the group. In order to mobilize the enthusiasm of each team member, the team members can take turns to be the team leader. In the scaffolding college English writing teaching, the mutual discussion among the group members is mainly concentrated in two stages, one is before the first draft is written, and the other is after the first draft is written. The discussion before the first draft is mainly to discuss the writing outline of each team member: whether the layout of the outline is reasonable, whether the intention is clear, whether each part of the outline has sufficient writing materials, whether the arrangement is reasonable, and whether the center can be highlighted. After the group discussion, the students revise or improve the outline according to the suggestions of the group members, and then complete the first draft within the specified time. After the students complete the first draft, a group discussion will be held again. The content of this discussion mainly includes: whether the wording of essay is appropriate, whether the grammar is correct, whether the expression is appropriate, and so on. Mutual discussion 
take students as the center, arouse students' interest in learning, and finally improve students' English level. mistakes in writing, while also saving the teacher's essay review time. Sometimes the group discussion will get deadlocked.

At this time, students can seek help from other groups through the online interactive platform, and solve the problems encountered in writing through cooperation and mutual assistance between the groups.

4) Setting up a multimodal comprehensive evaluation system scaffold:

In the multimodal auxiliary scaffolding college English writing teaching mode, teachers should use the modern network platform to construct a multimodal comprehensive evaluation system to comprehensively evaluate students' writing learning effects. The evaluation of students' writing learning effects should include three aspects: student selfassessment, intra-group mutual evaluation and teacher evaluation. Student self-assessment is the process by which students reflect on their writing performance, progress in writing, and the entire writing activity. The intra-group mutual evaluation mainly evaluates the enthusiasm of each group member to participate in the group discussion, the cooperation and exchange with other team members, and whether or not to make constructive comments and suggestions. The teacher evaluation mainly focuses on the evaluation of the student's final draft. Teachers generally give comprehensive comments on the evaluation of the final draft, both to affirm the advantages of the article, but also to point out its shortcomings.

In the multimedia network environment, student selfassessment, intra-group mutual evaluation and teacher evaluation can be carried out online with the method of multimodal evaluation. For example, intra-group mutual evaluation can either express their opinions on the class QQ group or blog by typing, or use the video software or audio software on the computer to record what you want to say and put it online. Compared with the traditional single-modal evaluation method based on words, the evaluation methods of combining various modes such as text, picture, audio and video are more intuitive, convenient and fast, and the evaluation results are more objective, effective and comprehensive.

In the multimodal auxiliary scaffolding college English writing teaching, the role of the teacher is to build the above four kinds of "scaffolds" for the students. With the help of the scaffolds, the students independently explore and collaborate to learn, and climb through these scaffolds step by step.

Then teachers will help students cross the "zone of proximal development" of writing level to achieve a new level of writing.

\section{CONCLUSION}

Applying multimodal auxiliary and scaffolding teaching theory to teaching can change the traditional teachercentered teaching model of college English writing class,

\section{REFERENCES}

[1] Department of Higher Education, Ministry of Education, College English Course Requirements, Foreign Language Teaching and Research Press, 2004, (8). (in Chinese)

[2] Lin Yuewu, Hu Yong. The use of scaffolding teaching mode in English teaching [J], 2010(10):108-109. (in Chinese)

[3] Vygotsky, L, Mind in Society: the Development of Higher Psychological processes [M]. MA.Havard University Press.1978

[4] Foreign Language Teaching, 2009, (-4): 15-20. (in Chinese)

[5] Wei Jian. Application of Multimodal Auxiliary Scaffolding Method in College English Translation Teaching [J]. Educational Exploration, 201-4, (2): 33-36. (in Chinese)

[6] Zhang Delu. The Application of Multimodal Discourse Theory and Media Technology in Foreign Language Teaching. (in Chinese)

[7] Zheng Shutang. Exploration and Practice: The Development of (in Chinese) College English Teaching, The Voice of Outer Research, 2008, (1). 